\title{
Informed Consent for Cross-Cultural Classroom Exercises: Teaching Tool or Wishful Thinking?
}

\author{
David E. L. Herst, Florida Atlantic University, USA
}

Promoting THE KIND OF VOLUntarism that is typically considered to be an ethical necessity when making personal choices is challenging in situations involving intercultural training. Both the need for and process of obtaining informed consent that promotes norms of voluntarism under conditions that occur in medical treatment and research situations is well recognized (Carmen \& Joffe, 2005). The parallel need for and process for obtaining informed consent in the postsecondary classroom is considered less often. Under some circumstances classroom exercises could be deemed unethical, particularly when they push for high levels of self-disclosure, violation of social or group norms and/or the questioning of core values and beliefs (Peterson, 2014). Ethical concerns are particularly important to instructors of cross-cultural coursework, which often includes experiential learning (role play, behavior observation, etc.). Experiential exercises require active thinking by students, which potentially leads to higher-order learning. Experiential exercises often use self-discovery to encourage students to consider alternatives to their core values and beliefs. would experience. This "inflicted insight" may be both difficult for individuals to absorb or even erroneous. The same could occur in crosscultural classroom exercises that are conducted without full disclosure of what will be done and/or what students may experience. The potential for harm suggests the ethical need for informed consent by participating students.

\section{Informed Consent}

Both the American Medical Association (AMA) and the American Psychological Association (APA) insist that certain requirements be met before medical procedures can be ethically performed or research can be ethically conducted (APA, 2010a; AMA Code of Medical Ethics, 2014; The Belmont Report, 1979). Chief among these is informed consent.

Principles of informed consent are rooted in respect for an individual's autonomy and consist of five elements (Meisel, Roth, \& Lidz, 1997, in Carmen \& Joffe, 2005; Eyler \& Jeste, 2006). Voluntarism means that a patient or research participant is free to make choices without coercion and "unfair persuasions and inducement" (Carmen \& Joffe, 2005: 637). Capacity means that a person is able to make a choice, understand a situation and rationally process information. Disclosure means providing enough information for a person to understand a procedure. Understanding is whether or not the patient or subject comprehends "the information given and appreciate(s) its relevance to her individual situation" (Carmen \& Joffe, 2005: 637). Finally, decision is the point when a person actually consents.

\section{Patient or Student?}

Medical and research models provide a useful starting point for analyzing the use of informed consent in intercultural instruction. Following the five elements of informed consent, to at least some degree, students attend universities and classes on a voluntary basis (volun- 
tarism); demonstrate capacity by making the choice to take specific courses (capacity); are given information about a class and its requirements (disclosure); have in principle the opportunity to ask instructors and other students for clarification should they lack understanding (understanding); and ultimately make the decision to participate, to attend a different class or request alternative assignments (decision). Yet the question remains: Is the general fulfillment of consent norms sufficient?

\section{The Challenge of Informed Consent in Cross- Cultural Instruction}

The challenges in obtaining fully informed consent in a cross-cultural course are eerily similar to obtaining informed consent from a patient or research participant. This starts with context, in this case of the classroom and enrollment in post-secondary education. Being part of a class in a university comes with the understanding that potentially uncomfortable concepts and beliefs that can promote self-reflection and selfcriticism are likely to be presented. Universities often codify this as a norm in their mission statements. For example, the mission statement for Florida Atlantic University (FAU), where the "step on Jesus" exercise became controversial (Peterson, 2014), clearly states that the organization is to promote "academic and personal development, discovery, and lifelong learning" (Florida Atlantic University, 2005). Yet FAU policy also states that students can be excused from coursework to participate in religious observation (Florida Atlantic University, n.d.). Thus FAU, like many other academic institutions, finds itself balancing potentially conflicting goals. In classroom exercises, particularly in cross-cultural coursework, the academic mission may overshadow religious protection in the minds of instructors and students.

Context expectations and norms are well researched (Trueblood, 2012; Weistein, 1991), and classroom expectations are not lost on students or instructors. Therefore, is a student's choice truly without undue influence when social expectations and norms of remaining in a classroom persist? Even with the option of exiting an exercise, are equivalent learning options really available to students without leaving the course? How does an instructor determine when student requests for alternative assignments are valid and when they are disingenuous?

The cultural background of the individual may also influence informed consent. Carmen and Joffe (2005) note that medical decisions in some cultural groups may reside in family members other than a patient. In the classroom, consent norms arising from the dominant US culture may be hard to apply when a student comes from a background where people are more likely to focus on group well-being above individual needs (Hall, 1976; Punnett, 2012). How can informed consent be obtained for students who come from a background where refusing to participate in a group exercise may not even be considered an option?

Other issues with using informed consent persist. Peterson (2014) questions whether young adults are self-aware enough to make decisions that may change or alter their self-conceptions and core beliefs. Research into self-determination in medical decisions would appear to answer in the affirmative (Weihorn \& Campbell, 1982), particularly when the health implications are serious (Scherer \& Repucci, 1988). However, there is no equivalent research using research consent or course-based exercises. So what happens when the context is a classroom, where the consequences for physical health and survival are lower, but where harmful personal and social implications are possible?

Concerning the element of disclosure, many social scientists fear that by divulging too much during informed consent the participant will alter his or her behavior, even in studies that do not have deception-based designs (Crow, Wiles, Heath, \& Charles, 2006). Similarly, cross-cultural instructors who promote higher-order learning may not mention the expected feelings an exercise is designed to elicit in the hopes that the student will learn by "experiencing" a new perspective. How can instructors provide true informed consent when doing so involves divulgence at a level that may short-circuit this process?

Lastly there is the element of understanding. The issue here may be quite simple: if the purpose of an exercise is to help an individual understand a concept, then attempting to get them to understand the exercise in advance would appear to make the exercise itself redundant. Why even conduct the exercise if understanding can be achieved in another way that does not pose the threat of inflicted insight? Hence, it may be impossible to meet the criterion of understanding as part of an informed consent process when doing classroom exercises.

\section{Addressing Inflicted Insight in Classroom Exercises}

Inflicted insight as a consequence of classroom exercises can be addressed in part by using a two-pronged approach. As in psychological research, in addition to obtaining informed consent, adequately debriefing students during post-exercise discussion is important. Guidelines for debriefing could be adapted from those put forth for psychological research (APA, 2010). Yet the point is moot if informed consent cannot be reliably obtained. By applying the medical and research models for meeting informed consent requirements to the needs related to crosscultural instruction, we can gain a better insight into these difficulties and consider appropriate solutions.

\section{Summary and Conclusions}

Classroom instructors of cross-cultural topics often find themselves administering exercises that are designed to elicit attitude changes and self-awareness. However such exercises may be unwelcome or have unintended consequences for students (Baumrind, 1985). The one-two punch of informed consent and post-exercise debriefing would appear to satisfactorily address this issue. Yet questions persist regarding 
whether informed consent is even possible. Specifically:

- The context of a classroom creates unavoidable pressure on students to complete assignments even when they find them disagreeable.

- Students from high-context cultures may be especially reluctant to opt out of exercises, or even voice concerns.

- Providing informed consent requires that instructors be properly trained in applying its principles.

Given these issues, informed consent does not appear to be either practical or even possible in a classroom setting. What, then, is a crosscultural instructor to do?

1. Consider the audience. Executives, senior government administrators and military officers as students may have different intercultural experiences and job requirements than traditional students.

2. Use less invasive exercises. Evaluate whether an exercise is specifically designed to invoke feels around core beliefs, norms and expectations rather than less central aspects of self. Modify or replace accordingly.

3. Use informed consent and post-exercise debriefing procedures as exercises unto themselves. By involving the students in analyzing cultural and contextual issues surrounding informed consent, instructors may be able to invoke a new set of norms for the classroom.

\section{Avoid using deception as a teaching tool.}

Studies of how informed consent is viewed and best utilized in crosscultural coursework could not be located. Yet ethically we must approach the subject of inflicted insight with great caution, at least until we better understand how it may be managed in a classroom setting.

\section{References}

American Medical Association. n.d. Code of medical ethics. http://www. ama-assn.org/ama/pub/physician-resources/medical-ethics/ code-medical-ethics.page.

American Psychological Association. 2010a. Ethical princials of psychologists and code of conduct. http://www.apa.org/ethics/code/ index.aspx?item $=11$.

American Psychological Association. 2010b. Publication manual of the American Psychological Association. Washington, DC: American Psychological Association.

Baumrind, D. 1985. Research using intentional deception: Ethical issues revisited. American Psychologist, 40: 165-174.

Carmen, M. G., \& Joffe, S. 2005. Informed consent for medical tretement and research: A review. The Oncologist, 10(8): 636-641.
Crow, G., Wiles, R., Heath, S., \& Charles, V. 2006. Research ethics and data quality: The implications of informed consent. International Journal of Social Research Methodology, 9(2): 83-95.

Eyler, L. T., \& Jeste, D. V. 2006. Enhancing the informed consent process: A conceptual overview. Behavioral Science and the Law, 24(4): 553-568. Florida Atlantic University. 2005. Mission statement. http://iea.fau.edu/fb05/mission9f.pdf.

Florida Atlantic University. n.d. Academic policies and regulations. http://www.fau.edu/academic/registrar/FAUcatalog/academics.php.

Hall, E. 1976. Beyond culture. New York: Anchor Press-Doubleday.

Meisel, A., Roth, L., \& Lidz, C. 1997. Toward a model of the legal doctrine of informed consent. American Journal of Psychiatry, 134(3): 285-289.

Peterson, M. F. 2014. Stepping on cultural and religious assumptions. AlB Insights, this issue.

Punnett, B. J. 2012. International perspectives on organizational behavior and human resource management (3rd edn). Armonk, NY: M.E. sharpe.

U.S. Deparment of Health, Education, and Welfare. 1979. The Belmont report: Ethical principals and guidelines for the protection of human subjects of research. http://www.hhs.gov/ohrp/humansubjects/guidance/belmont.html.

Scherer, D. G., \& Repucci, D. N. 1988. Adolescents' capacities to proivde voluntary informed consent: The effects of parental influence and medical dilemmas. Law and Human Behavior, 12(2)":123141.

Trueblood, J. S. 2012. Multialternative context effects obtained using an inference task. Psychonomic Bulletin Review, 19(5): 962-968.

Weihorn, L. A., \& Campbell, S. B. 1982. The competency of children and adolescents to make informed treatment decisions. Child Development, 53(6): 1589-1598.

Weinstein, C. S. 1991. The classroom as a social context for learning. Annual Review of Psychology, 42: 493-525.

David Herst (Email: dherst@fau.edu) is currently a full-time faculty member at Florida Atlantic University, where he has been involved in developing coursework at the graduate and undergraduate level, both live and on-line. He conducts research in skills-based leadership, and work and family conflict. David splits his time between academia and providing training and leadership development to Fortune 500 companies. Dr. Herst earned a BS degree in Psychology from the University of Wyoming, and both his masters and Ph.D. in industrial/ organizational psychology from the University of South Florida. 